\title{
Strategy and practise of external inspection in healthcare services - a Norwegian comparative case study
}

\author{
Charlotta Schaefer and Siri Wiig ${ }^{*}$
}

\begin{abstract}
Background: We could say that external inspections support improvement of healthcare services, but we know little about how. The aim of this study was to increase knowledge about how county governors, as external inspectorates of healthcare services, support and contribute to improvement through external inspections.

Methods: This is a comparative case study where data is based on qualitative interviews and analysis of government documents. Ten semi-structured interviews were conducted with inspectors representing two different county governors in Norway. Data analysis was based on systematic text condensation.

Results: The results showed that external inspectors customise their inspection strategy and approach to what they expect will improve practice of the inspected object. Inspectors were careful to practise the enforcement pyramid and appeared very patient when awaiting responses from the inspected object. The county governors had no systematic way to measure the effectiveness of regulatory performance in general or of external inspection in specific. The results confirmed some differences in practises between the two authorities in the study, in terms of attitudes to inspection and standard setting.

Conclusion: Compliance strategies were usually considered sufficient to start improvement processes within the inspected object. However, the current practise of external inspections lacked proper methods for measuring effect. For healthcare regulation and inspection in Norway and elsewhere to evolve, there is a need for stronger evidence of the effect of external inspection and better information to act upon when customising strategy and practise in order to legitimize use of public funds.
\end{abstract}

Keywords: Regulation, Healthcare, External inspection, Improvement, Norwegian, Strategy, Practise

\section{Background}

Regulation is a strong political instrument founded on a scientific base [1]. External inspection is widely used to regulate healthcare services and is important for citizens to receive qualified and safe services [2,3]. The purpose of external inspection, as part of regulatory practise, is to ensure that the laws are being followed, but inspections might also go a long way to improve the quality of services [4]. Research about how to regulate and inspect healthcare services is a growing field, but there is limited knowledge about how inspectors' practises contribute to the improvement of healthcare services [5]. Improvement of services

\footnotetext{
* Correspondence: siri.wiig@uis.no

Department of Health Studies, University of Stavanger, N-4036 Stavanger, Norway
}

(c) The Author(s). 2017 Open Access This article is distributed under the terms of the Creative Commons Attribution 4.0 International License (http://creativecommons.org/licenses/by/4.0/), which permits unrestricted use, distribution, and reproduction in any medium, provided you give appropriate credit to the original author(s) and the source, provide a link to the Creative Commons license, and indicate if changes were made. The Creative Commons Public Domain Dedication waiver (http://creativecommons.org/publicdomain/zero/1.0/) applies to the data made available in this article, unless otherwise stated. studies confirm that improvement work also are influenced by external resources and stakeholders [6, 7].

From a historical perspective, the scientific basis of how to regulate a specific service has moved between compliance and deterrence strategies. Compliance is an informal style of regulation emphasizing diplomacy, persuasion, and education rather than the routine application of sanctions to produce a compliance culture within the regulated organization. A regime promoting deterrence approaches is excessively legalistic, involving a strict imposition of standards [8,9]. Several researchers have claimed that the relationship between these two strategies is much more complex in the professional executive's daily work. Some researchers even say that 
deterrence strategies could destroy the improvement work after an inspection [10]. The establishment of a respectful and friendly relationship might prevent stricter remedies [11]. Current ways of conducting external inspection are influenced by risk-based and responsive regulation $[8,12]$. The really responding risk-based regulation framework makes an important contribution to the understanding of regulatory practises [13]. It shows the complexity of regulatory work and explains how the most valued parts of responsive and risk-based regulation can work together. The framework also involves other regulatory methods, such as smart regulation [6]. "The really responding" framework is not a practicable method but a solid theory that points out different regulatory concerns that regulators should act upon. To combine risk perception with responsiveness to the behaviour of the regulated object, demands that a regulator is adaptable and flexible. Five key elements are crucial for a regulator to become effective and achieve its objectives over time:

1. Knowledge of the behaviour, attitudes and culture of the regulated organisation

2. Knowledge and awareness about the regulator's own institutional settings

3. An understanding of how the logic of regulatory tools and strategies works

4. An ability to measure regulatory performance

5. Awareness of changes in any of these elements

To understand responsiveness and which strategic approach to choose towards the regulated object, the regulator needs information about behaviour, attitudes, and culture, when planning external inspection activities. Consideration of these elements will prepare the regulator to influence the regulated organisation in a specific direction. The institutional setting of the regulator will certainly be shaped by its relationship with and responsibility towards other organisations, including other regulatory agencies. Different regulatory agencies could possibly affect each other and the operation of regulatory practises. A "really responsive" regulation must be able to exert different strategies and tools, depending on the compliance of the regulated organization. Black and Baldwin [13] argue that different regulatory strategies often have divergent logics and the regulator needs to be pragmatic and understand the interaction among strategies. Another crucial element is the ability to assess regulatory performance when conducting external inspection. If regulators do not know if their efforts are effective, they cannot justify their societal function. Having ways to measure performance will not only help regulators to achieve their objectives, but also facilitate their ability to respond to challenges and non-compliant organisations. Finally, all regulatory agencies must handle changes when it comes to risk creators, unexpected events, political obligation, new knowledge, and the market. Any regulatory regime needs to relate to such changes to be a future informed and trustworthy regulator [13].

To sum up the "really responsive" framework [13], the literature notes that by taking precautions against the key elements in this theory, regulators are expected to be better prepared for challenges and unforeseen events that will appear in regulatory work. What makes the theory unique is the approaches to changes and acknowledgement of both internal and external factors which will affect the inspection process and possibilities of having the intended impact on regulatory compliance.

\section{Research problem}

Regulators and external inspectorates have to balance different interests and perspectives. It can be difficult to balance different roles of law enforcement and guidance [14]. There is an on-going debate on how to compose inspection teams, since team composition will have implications for inspection quality [15]. Differences in practises of external inspection disclose how standards and requirement should be set as an interpretation of legislation. Bureaucratic language and standards are sometimes difficult to explain to health care staff. Previous research indicates a weak correlation between quality improvement work in healthcare and the regulatory work to improve the same services [16]. Previous studies moreover argue that external inspection supports service improvement, but little is known about what makes that impact $[3,11]$. The aim of this study is to increase knowledge about how an external healthcare inspectorate supports and contributes to improvement through inspections of healthcare services. External inspection above all has an element of control, but how the inspectorate chooses to conduct the inspection may have a great impact on the processes that reinforce the improvement work.

The following research question guides this study:

How do external inspectorates customise their strategies and practises to support lasting changes and improvement in the healthcare services?

\section{The Norwegian context of external inspection in healthcare}

The Norwegian Board of Health Supervision (NBHS) is the national supervisory authority for Norwegian healthcare services and determines how external inspection is to be practised nationwide, for both primary and specialized healthcare, including social services. The NBHS publishes procedures and guidelines for the country's eighteen county governors to follow at the regional level.

The county governor is the governmental delegate in the counties and responsible for conducting external 
inspection in the healthcare services (both primary and specialized services including mental health). When it comes to inspection with healthcare services, inspection teams are set up with two to four inspectors, or more in rare cases. There are several types of inspection in Norway and they are mainly categorised as either eventbased or planned inspections. The most comprehensive type of external inspection is the planned system audit that examines the management system and whether the self-regulation mechanisms are being followed by a regulated institution [17]. In 2015 each county governor conducted between five and 62 planned inspections [18]. A total of 304 planned inspections were conducted in the primary care services and 37 in the specialized healthcare services [18]. The themes for the inspection are partly directed from the NBHS and partly founded on a risk based evaluation conducted by the 18 county governor offices [18]. The most common type of inspection is the event-based. The event-based inspections are induced by adverse events, by complaints from patients and next-of-kin, or by information from elsewhere such as the media. In 2015, the county governors conducted a total of 3325 event-based inspections in Norway [18]. The county governor and the NBHS evaluate information in each case of either adverse events or patient complaints, and consider the required follow-up (e.g. written information exchange, on site visit). The reported adverse events will be followed up, but not all result in an inspection on site including document review and interviews with the involved personnel and institution. Such a follow-up is usually reserved for the more severe cases.

\section{Methods}

\section{Study design}

To understand how the county governors customise their practises to contribute to improvement of services and identify differences in practises, we conducted a comparative case study of two county governors. The case study design is preferable because the study investigates custom attitudes and contextual meanings about how external inspection was practised [19].

\section{Case selection}

There are eighteen county governor offices in Norway. Departments of health and social services under the county governor are responsible for planning and conducting external inspection with health and social services in the county. They are also tasked with redistributing of national health policies. This study focuses on external inspection of health services only; inspection of social services is excluded. Two offices were chosen as cases, because the contextual factors were similar. Table 1 shows a description of the cases. The offices had approximately
Table 1 Contextual description of the cases

\begin{tabular}{lll}
\hline Context & $\begin{array}{l}\text { County } \\
\text { Governor I }\end{array}$ & $\begin{array}{l}\text { County } \\
\text { Governor II }\end{array}$ \\
\hline $\begin{array}{l}\text { Number of employees } \\
\text { in the department }\end{array}$ & 46 & 37 \\
$\begin{array}{l}\text { Number of hospitals } \\
\text { in the area of responsibility }\end{array}$ & 2 & 1 \\
$\begin{array}{l}\text { Number of municipalities } \\
\text { in the area of responsibility }\end{array}$ & 33 & 26 \\
\hline
\end{tabular}

the same number of municipalities in the counties and one university hospital each. These similarities made the cases suitable for comparison.

\section{Data collection}

Data collection is based on written policy documents, such as inspection guidelines and procedures, inspection reports, and qualitative interviews. In June and July 2015 we conducted individual semi-structured interviews with ten inspectors at the two county governor offices. The heads of the health and social services department in the county governor's office were contacted and invited to participate in the study. They recruited inspectors for interviews and all the inspectors that were interviewed had extensive experience with external inspection in healthcare. An interview guide was developed based on three themes: regulation strategies, improvement/change process, and interaction/reputation. The questions inquired into the approach of the inspector and how they conducted inspections. All interviews were held face to face in the county governors' offices. The interviews lasted between 45 to $65 \mathrm{~min}$.

The mandate and mission for county governor are described in their procedures, guidelines, legislation, and strategy documents. To arrive at a comprehensive understanding of the work of the county governor, these documents were collected and analysed. All the governing documents are available through the homepage of NBHS and the county governors. Inspection reports from the participating county governors were analysed to understand the practise and approaches to inspection. Because the requirements for anonymity in the ethical approval from the Norwegian social science data services (NSD), the reference to those documents cannot be included in this article.

\section{Data analysis}

The data was analysed within the cases before we conducted a cross-case analysis to compare the counties [20]. All interviews were transcribed and read through several times. We analysed the data according to a systematic text condensation approach [21]. This strategy is a systematic process of distilling the essential messages of the text, which makes the strategy appropriate for 
qualitative data. The text condensation consists of four steps: 1 . Identify themes to get an overview 2 . Identify meaning units 3 . Condensation - divide meaning units into new codes 4 . Re-contextualization of data - create meaning out of data.

\section{Results}

Findings from both cases will be presented in the following part. To distinguish the two cases, they are named county governor I (CG I) and county governor II (CG II). We compare and contrast the two cases and when county governors are mentioned in general, both are discussed.

\section{Understanding of behaviour, attitudes and culture of the regulated object}

The impression from both cases was that inspectors received a friendly and polite welcome when they first meet the object for inspection. However, they then experienced diverging interests within the inspected object. Inspectors at CG I claimed that the managers tend to be more optimistic about inspection and to see the benefits and the connection to improvement work. However CG I did not have the same impression about clinicians. The inspectors argued that clinicians perceived inspections as a burden that took time away from their work.

"Clinicians' consideration of inspections is that it's something the management should take care of. They won't accept the county governor telling them how things should be done." CG I

At CG II the informants had a different opinion about support from clinicians at the inspected object. The inspectors reported that clinicians usually appreciated inspections because they hoped for change and had seen organisational challenges over time. Conversely, inspectors at CG II argued that managers of the inspected object perceived the inspection as a distraction from their main tasks.

"In general, the [inspected] institutions do agree with our findings. But the manager often thinks that what we present is a little bit too much. The clinicians appreciate the inspection in another way. Maybe they are waiting for improvement and see the inspection as an opportunity to change. "CG II

Most of the contact before the first meeting of the external inspection is between the inspectors and the management of the inspected institution. The inspector's picture of the organisational practises of an institution depends on the information that he or she gets from the managers. The managers play a crucial part in the inspection. The results showed that some inspectors see a clear link between nonconformity and poor management of the inspected objects. Inspectors have no mandate to sanction or dismiss the managers, hence the inspectors argued they had to be innovative and support a weak leader or poor management to help them see what has been going wrong and give them ideas of how to resolve the nonconformities.

"We do meet institutions with a poor management. Then you can't do things easily, you must work systemically and gather information over time. To make the message clear, we have to put all our findings together and show the management what we' ve seen." CG I

Inspectors at CG II confirmed that nonconformities often were related to challenges with the management in the inspected institution. Although inspectors never give advice on re-organising or suggest that a manager should be removed, that is sometimes the implication after an inspection, when the inspection report is published.

\section{Understanding of the role of regulator}

Inspectors at CG I considered their mandate and the purpose of inspection as a control function. They argued that the control function could be exercised differently and that it is important to perform it in a way that contributes to improvement and organizational learning. However, they were aware of not confusing the roles of advice and control, by adhering strictly to the control procedure. As inspectors, they revealed discrepancies without giving advice on how to correct them. Inspectors left the task of taking the necessary corrective actions to the managers of the inspected institution.

\section{"Our culture is to stay reliable during the entire external inspection. We are very clear with what's going to happen from one time to another, we're strictly following the procedure and that's what give us legitimacy. "CG I}

Inspectors at CG II were also aware of not giving advice during inspection, but appeared more open-minded afterward when the audit report was completed. Results showed that inspectors at CG II did not suggest solutions, but argued that taking an advisory role could foster better learning processes. Inspectors claimed that taking the advisory role was a sign of their respect for the inspected object. Inspectors believed they had responsibility for the relationship and that not being available for discussions afterwards could undermine the improvement process at the inspected object. This 
conceptualization of the advisory role in the aftermath of inspections was not shared among inspectors at CG I.

"We have to distinguish between the red (control) hat and the green (advise) hat. When we are on inspection we wear the red hat. When we finish the report we can put on the green hat." CG II

Inspectors at both county governors observed that good communication skills were the most important professional skill when working with external inspections. Several informants considered communication skills even more important than professional background or medical competence. Inspectors at CG I argued that some inspectors held strong professional skills, but despite these skills, they were assigned administrative instead of inspection tasks, due to their shortcoming in the communication skills.

"You can't work with external inspections if you don't know how to talk to people, no matter how qualified you are or how good professional skills you might have." CG I

Every inspection team should be equipped with at least one legal professional and one physician. At CG I, inspection teams with three or four inspectors were assembled by the head of the department in consultation with the leader of the specific inspection. Together they selected the inspectors who were best suited to that inspection. At CG II, the inspection teams were put together based on a more democratic process that took inspectors interests, competence and capacity into consideration, in addition to the skills required from their medical and law background.

\section{Use of enforcement and logic of tools}

The county governors preferred compliance strategies to stronger enforcement actions. The contact between the county governor and the inspected object was a formal process based on written information transfer before and after the external inspection. The county governors reported that sending out the first informational letter about an upcoming inspection was sometimes enough to start the improvement process in the inspected object. The inspection objects were often aware of what needed to be changed and the informational letter could be enough to mobilise the improvement. Throughout the inspection, the county governors collect data by conducting interviews with medical and nursing staff, and managers, in combination with review of written information such as patient records, procedures, medical guidelines and documentation of the internal control system.
Dialogue was always the main preferred enforcement strategy, but when the county governor and the inspected object were unable to reach agreement, inspectors also used "time" as an important strategy. Sometimes inspectors had to wait for the inspected object to agree to reconsider taking corrective actions. Both county governors gave the inspected object time and several chances to act before resorting to deterrence strategies that implied use of sanctions. In rare cases a county governor made an onsite visit to verify that the promised changes had been completed.

Only a few informants had used enforcement strategies such as mulct. External inspection itself was considered sufficiently effective. Stronger enforcement actions could destroy the relationship between inspectors and the inspected object.

\section{"Change comes out of being in dialogue, rather than use enforcement actions." CG II}

The county governors define areas for improvement or "notices" as less severe failures than the nonconformities with the law. CGI and II applied different approaches to the notices. CG I had a clear strategy of issuing verbal notices in the final meeting or directly to the managers of the inspected object when addressing the "notices". They argued that only the serious failures qualified as nonconformities and should be included in the audit report. Minor issues should be handled face to face with the managers. On the other side, the practises at CG II included areas for improvement in the audit reports, because inspectors believed that formalizing the notices would help the institution's improvement work. Inspectors at CG II also believed that other healthcare institutions could learn from these kind of failures when reading the report. Written notices were considered more formal and implied a greater commitment and effort to making the change.

\section{Measurement of regulatory performances}

At the time of data collection, neither county governor had conducted any systematic evaluation of their own regulatory performance. Informants claimed that methodological challenges made it impossible. At the same time they expressed concerns about their inability to prove the effect of their work. After external inspections, the teams discussed the outcome and their experiences in an informal evaluation meeting. The evaluation meeting had an open agenda with no specific criteria for evaluation, but it offered a place to talk about less successful circumstances from the inspector's point of view, and was an important opportunity to discuss inspection practise. 
"We do evaluate ourselves and talk about what could have been done differently. But you asked me about something else, you asked if we measure effect of our own practises, and I'm afraid we don't. It actually concerns me." CG I

"I guess it's effective. But the question is about use of resources. Could we have achieved more with other methods?" CG II

Despite the lack of systematic measurement of performance in inspections, the informants from both county governors had several subjective experiences that inspection did affect healthcare improvement work. Inspectors claimed their knowledge about its effect in relation to external inspection activities in earlier cases.

\section{Change- and improvement work}

The results tell us that inspectors from both county governors did know several cases where the external inspection had helped the inspected objects in their internal improvement work. As inspectors, they found that failure in specific provisions of law had declined, because of earlier inspections where audit reports had been published and read by stakeholders and similar businesses.

\section{"Most of the [inspected] institutions want to achieve beyond compliance. They are doing more than we expect from them and try to solve things in a way that possibly can affect other institutions." CG I}

Both county governors reported that nonconformities directed to the management of the inspected objects got faster solutions and better information dissemination than did nonconformities directed to clinicians. This way of making the management responsible for nonconformities was in line with the increased focus on managerial accountability for quality and safety according to the law. Inspectors at both county governors preferred the managerial approach, contending that it better supported learning processes in the inspected institution.

CG II appeared more receptive to new and innovative methods of inspections with healthcare. This was demonstrated by on-going projects for trying out new regulatory methods. CG II was clearly interested in developing new practises of external inspection. Inspectors at CG II were also concerned with how the patient perspective could be better integrated into inspections and were about to start a project to accomplish this. At CG II, inspectors had positive experiences with the dissemination of knowledge from inspections to similar healthcare services by inviting other institutions to the first inspection meeting with a new inspection object. In contrast, inspectors at CG I appeared to be more loyal to current methods and was less interested in new developments. CG I followed the inspection procedures and guidelines, published by the Norwegian Board of Health Supervision, and did not question the fact that other regulatory methods could contribute to new and innovative ways of customising the inspection practice to achieve compliance with the healthcare law.

\section{Discussion}

Our main findings demonstrated institutional differences in attitudes and practise between the two county governors, a lack of measurement of regulatory performance, and a wide use of compliance dialogue-based strategies as a foundation for customizing practise to diverse regulated bodies.

Different attitudes about external inspection may have implications for the way in which inspectors approach an inspected object [14]. The two county governors differed in their attitudes towards the inspected object. While inspectors at CG I argued that the management of the inspected object understood the benefits of inspections and the clinicians did not, the inspectors at CG II reported the opposite. Other studies argue that healthcare improvement needs to be vertically and horizontally rooted in an organisation [16]. Our study illustrates a potential lack of acknowledgement of external inspection as a mean to boost the internal quality and safety improvement work in the healthcare service organizations. This marks a call for the importance of motivating an upcoming external inspection at every level in the organisation of the inspected object, not only the management or the clinicians. Management as a discipline has become more important in society and in healthcare [8]. The county governors in our study put a major effort in the correspondence with the management level as inspectors held managers accountable for the improvement work [22]. These finding are in line with other studies where managers to a stronger degree are held accountable for improving quality and safety in healthcare [23]. However, holding the management responsible for nonconformities, does not seem compromise the need of actions towards medical staff in healthcare [24].

Another difference between the two county governors was related to the way they reacted to areas for improvement. Areas for improvement can be described as findings during inspection that were not consistent with best practice, but not serious enough to be classified as nonconformity. According to Hood et al. standards should be clearly defined and uniformly practised [9], but our findings showed different inspection practise in relation to the areas for improvement. A recent Norwegian public report handed over to the Ministry of Health and Care Services reported similar findings, and pointed to the need of reducing inequality of inspection practise 
between Norwegian county governors [25]. CG I reported areas for improvement verbally in the summary meeting, while CG II included area of improvement in the written inspection report. In a learning perspective, both CGs were aware of how the inspected object could learn from failures in their own organisation [26, 27]. The strategy of conveying areas if improvement verbally is supported by research showing that face-to-face feedback improved the learning effect better than written feedback [28]. However, Crossan et al. argue that new knowledge needs to be institutionalised in an organisation before real changes can appear [26]. To formalize areas of improvement in the inspection report could be understood as a strategy to support institutionalised learning processes, as it could be detrimental for changes of organizational practises if the areas of improvement are to be discussed only at the management level.

The difference in how inspections teams were composed was linked to the required professional and personal skills. Despite professional competence, such as legal and medical knowledge, CG I was concerned about inspectors having the right personal skills. Both CGs were accurate about all inspections teams having legal and medical competence but CG II practised a more democratic selection when composing inspection teams; its inspectors could request the inspection they wanted to contribute to. Most of the inspectors at both CGs were either physicians or legal professionals. One recurrent topic related to correct professional background as a prerequisite for credibility and legitimacy from the healthcare services [14]. According to the patient safety report from World Innovation Summit for Health from 2015, socio-technical systems with high quality and safety level, depend on multidisciplinary approaches to problem solving [29]. Maybe this also is a task for county governors when controlling the healthcare system through inspection. The staffing at the CGs may have a too narrow competence composition as healthcare problems are complex and require diverse perspectives to understand the risk picture. A stronger multidisciplinary approach might contribute to a broader understanding of the issues in the daily work of inspectors [30].

Empirical knowledge about regulatory performance and effect is limited [13, 31], but still measurement of one's own performance is emphasised as a key factor for sound inspection practise in the "really responsive" framework [13]. Despite poor empirical knowledge about effectiveness of external inspection, there have been some studies investigating both reliability and validity of inspection and audit practise. External inspection standards in healthcare varies between investigating organisational behaviour, healthcare professionals or estimating patient outcomes, but Flodgren et al. argue in their systematic review that there is too few studies in this field to draw a conclusion about the effectiveness of the external inspections [31]. According Risso-Gill et al. [32], there is limited consistency across Europe on the regulation of medical professionals, and there is variation in the range of topics that the regulatory bodies oversee. But, almost all regulatory bodies follow up healthcare quality and safety, and topics related to trust, respect and reputation [32]. Moreover, there is variation across Europe in the targets of the inspections and whether or not inspections focus mainly on the organization and management or on the healthcare professionals [24]. In Norway, our study has similarities with previous studies [25,33], pointing at a regulatory shift towards stronger emphasis on a system perspective targeting the management and organisation in external inspection of the healthcare services.

Since external inspection systems, such as the NBHS and the County Governors in Norway, almost always involve inspectors who assess organizational or professional performance against standards, the credibility of a regulatory body can be threatened if inspectors' assessments of performance are unreliable [15]. A recent study focusing on the reliability of inspectors' assessment among inspectors inspecting of English acute hospitals, showed that the level of agreement varied between inspectors and groups of inspectors made more reliable assessment in inspections compared to what individual inspectors did. The disagreement between inspectors partly related to diverse weight given to contextual factors in the assessment [15]. Inspector judgement has also been studied in the Netherlands. The Dutch study pointed out that not one single instrument could evaluate the complexity and multidimensional work of inspectors [34]. Relating these findings to our study, there seems to be evidence to support establishing arenas that allow for appropriate discussions between inspectors to improve reliability of their assessment but also to evaluate their own practice to ensure more equal weighting of factors in their assessment [15].

A few years ago, the Care Quality Commission (CQC) in the UK, developed a new standard of objective collection and analysis of data, after several severe failures in English hospitals [35]. The new strategy of CQC intended to base inspections on reliable facts to make better risk assessments, through the statistical surveillance tool called "Intelligent monitoring". Due to limited resources to conduct on-site inspections, the CQC applies this statistical surveillance tool to help identify and prioritise providers for inspections. The effect of "intelligent monitoring" has recently been evaluated with depressing results. Griffiths and colleagues concluded that the "intelligent monitoring" tool could not predict outcome of English hospitals and a new approach to inspection planning is required [36]. 
A study by Dixon [37] stated that the baseline for measuring effectiveness was depending on how national projects to measure and improve the quality of care were developed. Dixon concluded that because of absence of agreement of best practise in quality improvement, inspection standards vary a lot [37]. Maybe the most serious consequence of difficulties in measuring effect of performance in external inspection, is the use of public funds without actually knowing its social benefits. Although the measurement of effect is missing, our study confirms that external inspection could be an important contribution to the improvement of healthcare services $[4,11,38]$. Informants reported that improvement work started because of external inspections and had knowledge about on-going improvement project based on published audit reports. Such an example might indicate that external inspections do have an effect, even though we do not have systematic empirical knowledge about it. Future studies should focus on collaboration with regulatory bodies and regulated objects to design regulatory interventions with possibilities of measuring effects on both organizational process and patient outcome dimensions. Both CGs use a compliance strategy with dialogue-based inspections as the favoured strategy to customize their practise and effect change in the inspected object [39]. The result showed that the most important inspection strategy to facilitate improvement was to build a sound relationship through constructive dialogues with the inspected object. Furthermore, inspectors were found to be reluctant about using different enforcement actions, like mulct, because they believed it could interfere with their ability to change organisational behaviour. Some earlier studies support these findings of the wide use of compliance strategies $[5,13,40]$. But there are also studies that claim that regulators' ability to use enforcement action is crucial to promote change $[12,41]$.

\section{Conclusion}

Our study contributes to the knowledge on how county governors, as an external inspectorate, work to customise strategy and practise to support improvement and lasting changes in healthcare services. External inspection is above all about controlling the services, but the control can be practised in a way that will support the internal improvement work. Inspectors are very careful about giving advice during inspection due to fear of conflicts of interests [14]. County governors focus on establishing a friendly dialogue in the starting phase of an inspection since it might promote quality improvement [13]. Inspectors consider good communication and relational skills as crucial to facilitate change and improvement through inspection. County governors also customise their practise of presenting nonconformities to what they expect can enable good solutions for the regulated object. Therefore county governors preferred to direct nonconformities towards the management [38]. Findings show that county governor are almost reluctant about taking enforcement actions, because they believe it might weaken the relationship and undermine their possibilities to facilitate change in organisational behaviour [5]. Our study increases the knowledge about the role of regulators and inspectorates, which is important to the evolution of inspection methods and strategies. This knowledge is also important to reduce inequalities of inspections practises in Norway and elsewhere.

\section{Abbreviations}

CG: County governor; CQC: Care Quality Commission; NBHS: Norwegian Board of Health Supervision

\section{Acknowledgements}

We would like to thank the county governors for their participation in the study and for sharing their knowledge and experience with us. We would also like to thank the reviewers for their valuable input to improve the paper.

Funding

University of Stavanger, Norway.

Availability of data and material

Please contact authors for data requests.

Authors' information

CS holds a master of science in change management.

SW is full professor of quality and safety in healthcare systems.

Authors' contributions

CS and SW designed the study. CS collected the data and had the main responsibly for the data analysis with supervision from SW. Both authors drafted the manuscript and have read and approved to the final revised version of the manuscript.

\section{Competing interests}

None.

Consent for publication

Not applicable.

Ethical approval and consent to participate

Ethics approval for this study was obtained from Norwegian social science data services (NSD) in April 2015, reference number: 43182. All informants signed a written consent to participate in the study, as required by NSD.

This article has not been published or sent to submission before.

Received: 11 January 2017 Accepted: 20 February 2017

Published online: 03 March 2017

References

1. Humphrey JC. A scientific approach to politics? On the trail of the Audit Commission. Critical Perspectives on Accounting. 2002: doi:10. 1006/cpac.2000.0490

2. Davis H, Downe J, Martin, S. External Inspection of local government. Driving improvement or drowning in detail. The Joseph Rowntree foundation. 2001. http://www.jrf.org.uk/sites/default/files/jrf/migrated/files/ 1859352979.pdf. Accessed 3 Oct 2016

3. Shaw CD, Braithwaite J, Moldovan M, Nicklin W, Grgic I, Fortune T, Whittaker S. Profiling health-care accreditation organizations: an international survey. Int J Qual Health Care. 2013;25(3):222-31.

4. Walshe K. Regulating Healthcare : A Prescription for Improvement? Berkshire: McGrawHill Education; 2003.

5. Healy J. Improving health care safety and quality : reluctant regulatorsLaw, ethics and governance. Farnham Surrey: Ashgate; 2011. 
6. Gunningham N, Sinclair D. Organizational Trust and the Limits of Management-Based Regulation. Law \& Society Review. 2009; doi:10.1111/j. 1540-5893.2009.00391.x

7. Kagan RA, Gunningham N, Thornton D. Explaining Corporate Environmental Performance: How Does Regulation Matter? Law \& Society Review. 2003; doi:10.1111/1540-5893.3701002

8. Baldwin R, Cave M, Lodge M. Understanding regulation : theory, strategy, and practice. 2nd ed. Oxford: Oxford University Press; 2012.

9. Hood C, Rothstein H, Baldwin R. The government of risk: understanding risk regulation regimes. Oxford: Oxford University Press; 2001.

10. Lloyd-Bostock SM, Hutter BM. Reforming regulation of the medical profession: The risks of risk-based approaches. Health Risk Soc. 2008; doi:10. 1080/13698570701782460

11. Healy J, Braithwaite J. Designing safer health care through responsive regulation. Med J Aust. 2006;84:56-9.

12. Ayres I, Braithwaite J. Responsive regulation: Transcending the deregulation debate. Oxford: Oxford University Press; 1992.

13. Black J, Baldwin R. Really responsive risk-based regulation. Law Policy. 2010;32:181-213.

14. Reiman T, Norros I. Regulatory culture: balancing the different demands of regulatory practice in the nuclear industry. In: Kirwan B, editor. Changing Regulation - Controlling Hazards in Society. Oxford: Pergamon; 2002. p. 175-92.

15. Boyd A, Addicott R, Robertson R, Ross S, Walshe K. Are inspectors' assessment reliable? Rating of NHS acute hospital trust services in England. J Health Serv Res Policy. 2016; doi: 10.1177/1355819616669736

16. Wiig S, Lindøe PH. Patient safety in the interface between hospital and risk regulator. J Risk Res. 2009; doi: 10.1080/13669870902952879

17. Braut GS, Holmboe. Pasientsikkerhet - dagens struktur. In: Aase K, editor. Pasientsikkerhet - teori og praksis. Oslo: Universitetsforlaget; 2015. p. 47-61.

18. Helsetilsynet: Tilsynsmelding 2015. http://www.helsetilsynet.no/no/ publikasjoner/tilsynsmelding (2016). Accessed 28 Jan 2017.

19. Blaikie N. Designing Social Research. 2nd ed. Cambridge UK: Polity Press; 2010.

20. Yin RK. Case study research : design and methods. 5th ed. Los Angeles: Sage; 2014.

21. Malterud K. Systematic text condensation: a strategy for qualitative analysis. Scan J of Pub Health. 2012;40:795-805.

22. Nembhard IM, Edmondson AC, Ramanujam R, Rousseau DM. Making it safe: the effects of leader inclusiveness and professional status on psychological safety and improvement efforts in health care teams. J of Org Beh. 2006. doi:10.1002/job.413.

23. Tavare A. Where are we with transparency over performance of doctors and institutions? B M J. 2012; doi: https://doi.org/10.1136/bmj.e4464.

24. Walshe K, Archer J. Medical regulation: more reforms are needed. B M J. 2014; doi:10.1136/bmj.g5744

25. Norwegian public report. Med åpne kort: Forebygging og oppfølging av alvorlige hendelser i helse- og omsorgstjenestene. Departementenes sikkerhets- og serviceorganisasjon.2015. https://www.regjeringen.no/no/ dokumenter/nou-2015-11/id2459861/ Accessed 5 Nov 2015.

26. Crossan MM, Lane HW, White RE. An organizational learning framework: From intuition to institution. Acad Manag Rev. 1999;24:522-37.

27. Weick KE, Sutcliffe KM. Hospitals as cultures of entrapment: a re-analysis of the Bristol Royal Infirmary. Calif Manag Rev. 2003;45:73-84.

28. Hansen MT, Nohria N, Tierney T. What's your strategy for managing knowledge? Harv Bus Rev. 1999;77:106.

29. Pronovost PJ, Ravitz A, Kennedy S, Stoll R. Transforming Patient Safety. A sector-wide systems approach. WISH report. 2015. http://www.wish-qatar.org/ research/reports/patient-safety-en. Accessed 7 Dec 2015.

30. Carayon P, Wetterneck TB, Rivera-Rodriguez AJ, Hundt AS, Hoonakker P, Holden R, Gurses AP. Human factors systems approach to healthcare quality and patient safety. Applied Ergonomics. 2013; doi:10.1016/j.apergo.2013.04.023

31. Flodgren G, Pomey MP, Taber SA, Eccles MP. Effectiveness of external inspection of compliance with standards in improving healthcare organisation behaviour, healthcare professional behaviour or patient outcomes. The Cochrane Library. 2011; doi:10.1002/14651858.CD008992.pub2

32. Risso-Gill I, Legido-Quigley H, Panteli D, McKee M. Assessing the role of regulatory bodies in managing health professional issues and errors in Europe. Int J Qua Health. 2016;26:348-57.

33. Wiig S. A contribution to risk management in public sector. Stavanger: Doctoral thesis; 2008
34. Tuijn SM, Robben PB, Janssens FJ, van den Bergh $H$. Evaluating instruments for regulation of healthcare in the Netherlands. J Eva Clin Prac. 2009; doi: 10.1111/j.1365-2753.2010.01431.x

35. Glasper A. The Care Quality Commission hospital inspection process. British J Nurs. 2015;25:792-3.

36. Griffiths $A$, Beaussier AL, Demeritt $D$, Rothstein $H$. Intelligent monitoring? Assessing the ability of the Care Quality Commision's statistical surveillance tool to predict quality and prioritise NHS hospital inspections. BMJ Qual Saf. 2016; doi:10.1136/bmjqs-2015-004687.

37. Dixon N. Proposed standards for the design an conduct of a national clinical audit or quality improvement study. Int J Qua Health. 2013;25:357-65.

38. Hovlid E, Høifødt H, Smedbråten B, Braut GS. A retrospective review of how nonconformities are expressed and finalized in external inspections of health-care facilities. BMC Health Services Research. 2015; doi:10.1186/ s12913-015-1068-9

39. Gunningham N. Enforcement and Compliance Strategies. In: Baldwin RC, Cave M, Lodge M, editors. The Oxford Handbook of Regulation. London: Oxford University Press; 2010

40. Brennan TA. The role of regulation in quality improvement. Milbank Q. 1999;76(4):709.

41. Nielsen $\mathrm{VL}$, Parker $\mathrm{C}$. Testing responsive regulation in regulatory enforcement. Regulation \& Governance. 2009. doi:10.1111/j.1748-5991. 2009.01064.x

\section{Submit your next manuscript to BioMed Central and we will help you at every step:}

- We accept pre-submission inquiries

- Our selector tool helps you to find the most relevant journal

- We provide round the clock customer support

- Convenient online submission

- Thorough peer review

- Inclusion in PubMed and all major indexing services

- Maximum visibility for your research

Submit your manuscript at www.biomedcentral.com/submit
) Biomed Central 